\title{
RESECTION FOR BRONCHOGENIC CARCINOMA INVOLVING THE CARINA: LONG-TERM RESULTS AND EFFECT OF NODAL STATUS ON OUTCOME
}

John D. Mitchell, MD

Douglas J. Mathisen, MD

Cameron D. Wright, MD

John C. Wain, MD

Dean M. Donahue, MD

James S. Allan, MD

Ashby C. Moncure, MD

Hermes C. Grillo, MD
Objective: Bronchogenic carcinoma in close proximity to or involving the carina remains a challenging problem for thoracic surgeons. The operative procedures to allow complete resection are technically demanding and can be associated with significant morbidity and mortality. Little is known about long-term survival data to guide therapy in these patients.

Methods: We conducted a single-institution retrospective review.

Results: We have performed 60 carinal resections for bronchogenic carcinoma: 18 isolated carinal resections for tumor confined to the carinal or proximal main stem bronchus; 35 carinal pneumonectomies; 5 carinal plus lobar resections, and 2 carinal resections for stump recurrence after prior pneumonectomy. Thirteen patients $(22 \%)$ had a history of lung or airway surgery. The overall operative mortality was $15 \%$, improved from the first half of the series $(20 \%)$ to the second half $(10 \%)$, and varied according to the type of resection performed. Adult respiratory distress syndrome was responsible for 5 early deaths, and all late deaths were related to anastomotic complications. In 34 patients, all lymph nodes were negative for metastatic disease; 15 patients had positive N1 nodes, and 11 patients had positive N2/N3 nodes. Complete follow-up was accomplished in $90 \%$, with a mean follow-up of 59 months. The overall 5-year survival including operative mortality was $42 \%$, with 19 absolute 5-year survivors. Survival was highest after isolated carinal resection $(51 \%)$. Lymph node involvement had a strong influence on survival: patients without nodal involvement had a 5-year survival of 51\%, compared with $32 \%$ for patients with $\mathrm{N} 1$ disease and $12 \%$ for those with N2/N3 disease.

Conclusions: This constitutes one of the largest single-institution reports on carinal resection for bronchogenic carcinoma involving the carina. Morbidity and mortality rates are acceptable. The overall survival including operative mortality is $42 \%$. Positive N2/N3 lymph nodes may be a contraindication to surgery because of poor prognosis. (J Thorac Cardiovasc Surg 2001;121:465-71)
$\mathrm{B}^{\mathrm{n}}$ ronchogenic carcinoma in close proximity to or involving the carina remains a challenging problem for thoracic surgeons. Although the majority of patients with this disease are not candidates for surgical therapy, a select subset of individuals will not have disseminated disease or concomitant direct invasion of other vital

From the General Thoracic Surgical Unit, Massachusetts General Hospital, and the Department of Surgery, Harvard Medical School, Boston, Mass.

Read at the Twenty-sixth Annual Meeting of The Western Thoracic Surgical Association, The Big Island, Hawaii, June 21-24, 2000.

Copyright (C) 2001 by The American Association for Thoracic Surgery

$0022-5223 / 2001 \$ 35.00+0 \quad 12 / 6 / 112832$

doi:10.1067/mtc.2001.112832 mediastinal structures. Techniques to allow complete surgical resection are available for this latter group of patients, ${ }^{1,2}$ but concerns over perioperative morbidity and mortality rates and uncertainty regarding long-term survival have limited their widespread use. To better understand these issues, we have reviewed our experience with carinal resection and reconstruction for bronchogenic carcinoma, including the long-term outcome for these patients.

\section{Patients and methods}

This study comprises all patients who underwent primary resection and reconstruction of the carina for bronchogenic carcinoma at the Massachusetts General Hospital from 1973 to 1998. This group included patients with lung cancer 
extending proximally to approach or involve the carina, those who had tumor involvement confined to the very proximal main bronchus or carina, making concomitant lung resection unnecessary, and patients with recurrent carcinoma arising in the bronchial stump after prior pneumonectomy. Information and follow-up were obtained from hospital charts, office records, referring physicians, and direct contact with the patients or patients' families.

Preoperative assessment. Careful preoperative evaluation remains the key to success in carinal surgery. Special attention was given to coexisting disease states and the possibility of distant metastases. Patients are strongly encouraged to stop smoking well before the planned procedure. Steroid therapy is tapered and discontinued because of detrimental effects on airway healing. If needed for palliation, a bronchoscope can often be used to core out the airway in patients with significant airway obstruction before the operation. ${ }^{3}$ Complete pulmonary function tests, including arterial blood gas analysis and ventilation/perfusion scans, were routinely obtained to assess preoperative and estimated postoperative lung function. Radiologic assessment typically included computed tomography of the chest, linear tomograms of the trachea and main stem bronchi, or both. Chest computed tomography remains the best single study to assess direct tumor involvement of the airway and other mediastinal structures, evaluate the presence of significant mediastinal adenopathy or other evidence of intrathoracic metastases, and judge the degree of lung parenchymal disease. Linear tomography, although no longer routinely performed, is extremely useful in assessing the extent of involved and uninvolved airway, particularly with regard to planning airway reconstruction. Other radiologic studies, including computed tomographic scanning of the head, bone scan, and more recently positron emission tomographic scanning, are obtained as indicated to evaluate for evidence of metastatic disease.

Anesthesia. Close cooperation between the anesthesiologist and the surgeon is essential. An epidural catheter is placed before initiation of the procedure to provide for postoperative analgesia. An inhalational induction technique is used until the airway is secured. Anesthesia is then maintained with inhalation agents combined with short-acting narcotics and paralytics, with allowance for planned extubation at the end of the procedure. A traditional double-lumen tube is not used, because such tubes are too stiff and cumbersome and tend to interfere with airway resection and reconstruction. Instead, we prefer to use an extra-long, armored endotracheal tube that can be positioned in one of the main stem bronchi under bronchoscopic control. The oral tube is withdrawn into the proximal trachea at the time of airway division. The opposite (or remaining) bronchus is intubated across the operative field with sterile connective tubing and an endotracheal tube. The patient's lungs are ventilated across the field in an intermittent fashion, with removal of the tube to allow for precise placement of anastomotic sutures. As the main airway (tracheobronchial) anastomosis is approximated, the original extra-long tube is advanced beyond the area of anastomosis, and ventilation is resumed via the oral tube as the anastomotic sutures are tied. Secondary anastomoses are then completed without the need for further tube manipulation. After completion of all anastomoses, the endotracheal tube is positioned in the proximal trachea to test for anastomotic pneumostasis and to allow for direct visualization of the anastomoses via a bronchoscope. Should the need arise, the anesthesia team must be familiar with optional ventilatory techniques, including high-frequency and independent lung ventilation. Cardiopulmonary bypass was not used in this cohort of patients and in our experience is not needed for support during carinal surgery.

Assessment of resectability. All patients were examined with a rigid bronchoscope to allow for precise visual assessment of the involved airway, including actual measurements to help determine resectability and plan airway reconstruction. Occasionally, endoscopic debulking of endobronchial tumor was accomplished with the rigid bronchoscope. This was performed when respiratory failure resulting from airway obstruction was present, to assist in the management of postobstructive pneumonia before definitive resection, and to facilitate airway management during airway reconstruction. The majority of patients underwent mediastinoscopy, with some variation due to surgeon preference. The presence of involved upper mediastinal lymph nodes precluded resection. In addition to assessment of nodal status needed for cancer staging, mediastinoscopy permits evaluation of the extraluminal extent of the tumor. This procedure also assists in mobilization of the upper airway through development of the pretracheal plane. For this reason, mediastinoscopy should be done at the time of the planned resection.

Incision. Access to the carina is best achieved through a right posterolateral thoracotomy, typically via the fourth or fifth intercostal space. An exception to this approach occurs in cases in which a left carinal pneumonectomy is required. This may be best accomplished through a left thoracotomy with mobilization of the aortic arch, bilateral sequential thoracotomies, or with a "clamshell" (bilateral submammary, transsternal) incision.

Technique of carinal resection. The techniques used for carinal resection and reconstruction at our institution have been reported elsewhere. ${ }^{1,2}$ A few points pertaining to resection of malignant processes deserve re-emphasis. Frozen section analysis of resected airway margins by pathologists should be immediately available. Extensive dissection beyond the area of the tumor and the subsequent anastomosis is avoided because of concerns over airway devascularization. For this reason, extended lymphadenectomy is discouraged and only those lymph nodes involved with or immediately adjacent to the main tumor are resected.

Special attention should be paid to maneuvers used to reduce tension on the newly constructed airway anastomosis. Development of the pretracheal plane, either through mediastinoscopy or via the operative field, can provide some mobility to the upper airway. Freeing the ventral surface of the left main bronchus can produce limited mobility in an analogous manner. Care must be taken to avoid disrupting the blood supply to the airway, which approaches the trachea from the lateral aspect. The use of an inferior hilar release can 
provide a significant reduction in anastomotic tension. This is accomplished by creating a U-shaped incision in the pericardium beneath the hilum after division of the inferior pulmonary ligament. Even more mobility to the hilum can be obtained by performing a complete hilar release, dividing the pericardium circumferentially. When this latter release is being performed, the posterior vascular and lymphatic attachments to the hilum should be preserved. In general, use of a right hilar release should be considered in any carinal operation in which right-sided lung parenchyma is preserved; a left hilar release results in less cephalad mobility because of the aortic arch. We have found laryngeal release maneuvers to be of limited use in carinal surgery because they have not translated into more distal tracheal mobility. Finally, mild flexion of the neck allows the upper trachea to devolve into the mediastinum and is used at the time the anastomotic sutures are secured. This degree of neck flexion is maintained for several days postoperatively (by a stitch between the chin and the skin overlying the manubrium) and, more important, discourages neck extension, which places undue tension on the newly constructed airway anastomosis.

Adjuvant therapy. In general, postoperative radiation therapy was given to all hospital survivors who had not had an anastomotic complication or who had undergone prior extensive mediastinal radiotherapy. The rationale for this approach stems from the limited margins inherent in carinal resection and reconstruction for carcinoma; the desire for a wide resection margin is counterbalanced by the need for a safe, tension-free reconstruction. This is particularly true in cases in which an anastomosis between the trachea and left main bronchus is planned (eg, right carinal pneumonectomy) where the airway resection should be limited to $4 \mathrm{~cm}$ or less. Radiation therapy is given 4 to 6 weeks after the operation, after airway healing is documented via a bronchoscope. The usual dose is approximately $5000 \mathrm{cGy}$.

Statistical methods. Survival data were calculated according to the Kaplan-Meier method from the date of operation and included postoperative deaths. ${ }^{4}$ Differences in survival between groups were tested for significance by the log-rank test. ${ }^{4}$ Survival analysis was completed with the use of the computer software program STATA (Stata Corporation, College Station, Tex).

\section{Results}

From 1973 through 1998, 60 patients underwent resection of the carina with primary (single-stage) airway reconstruction at our institution. The patient characteristics are detailed in Table I. The prior lung or airway operations in 13 patients included 2 pneumonectomies, 8 lobar or bilobar resections, 2 wedge resections, and 1 localized tracheotomy and tumor excision. Preoperative radiation therapy was given as part of a neoadjuvant protocol (4 patients), as adjuvant therapy of a prior malignant tumor (4 patients), or for primary therapy for what was presumed to be an inoperable lesion (1 patient).
Table I. Patient characteristics

\begin{tabular}{lc}
\hline $\begin{array}{l}\text { No. of patients } \\
\text { Age (y) }\end{array}$ & 60 \\
$\quad$ Mean & 55.6 \\
Range & $8-73$ \\
Sex & \\
$\quad$ Male, n (\%) & $42(70 \%)$ \\
Female, n (\%) & $18(30 \%)$ \\
Prior lung or airway surgery, n (\%) & $13(22 \%)$ \\
Prior radiation therapy, n (\%) & $9(15 \%)$ \\
Diagnosis, n (\%) & \\
$\quad$ Squamous cell carcinoma & $42(70 \%)$ \\
Adenocarcinoma & $11(18 \%)$ \\
Large cell carcinoma & $4(7 \%)$ \\
Bronchoalveolar carcinoma & $1(1.6 \%)$ \\
Small cell carcinoma & $1(1.6 \%)$ \\
Mixed squamous/small cell carcinoma & $1(1.6 \%)$ \\
\hline
\end{tabular}

Preoperative evaluation. All patients underwent preoperative bronchoscopy. Five patients required preoperative endoscopic debulking ("coreout") of the endobronchial tumor before definitive resection. Mediastinoscopy was performed in 48 patients (80\%) and yielded involved N2/N3 nodes in 4 patients, leading to additional treatment before resection through institutional protocols assessing neoadjuvant therapy.

Operative procedure. A right posterolateral thoracotomy was used in all but 3 patients. A bilateral thoracotomy approach was used in 1 patient for a left carinal pneumonectomy; in another patient requiring a similar resection, a bilateral submammary, or "clamshell," incision was used. In 1 patient who underwent a right carinal pneumonectomy, a median sternotomy was used.

Carinal resection and reconstruction without pulmonary resection was accomplished in 18 patients. These individuals had carcinoma limited to the carina, and the degree of main stem bronchial involvement varied, dictating the type of reconstruction performed. In 3 patients in whom a very limited amount of airway was resected, a "neocarina" was constructed from the right and left main stem bronchi, with subsequent implantation to the distal trachea. In 12 patients in whom a larger airway resection was required, the trachea was brought together end to end with the left main stem bronchus; the right main stem bronchus was implanted into the side of the trachea (11 patients) or left main stem (1 patient). Finally, in 3 patients in whom extensive airway resection prohibited approximation of the trachea and left main stem bronchus because of anticipated anastomotic tension, the trachea was brought end to end with the right main stem bronchus with implantation of the left main stem into the bronchus intermedius. 


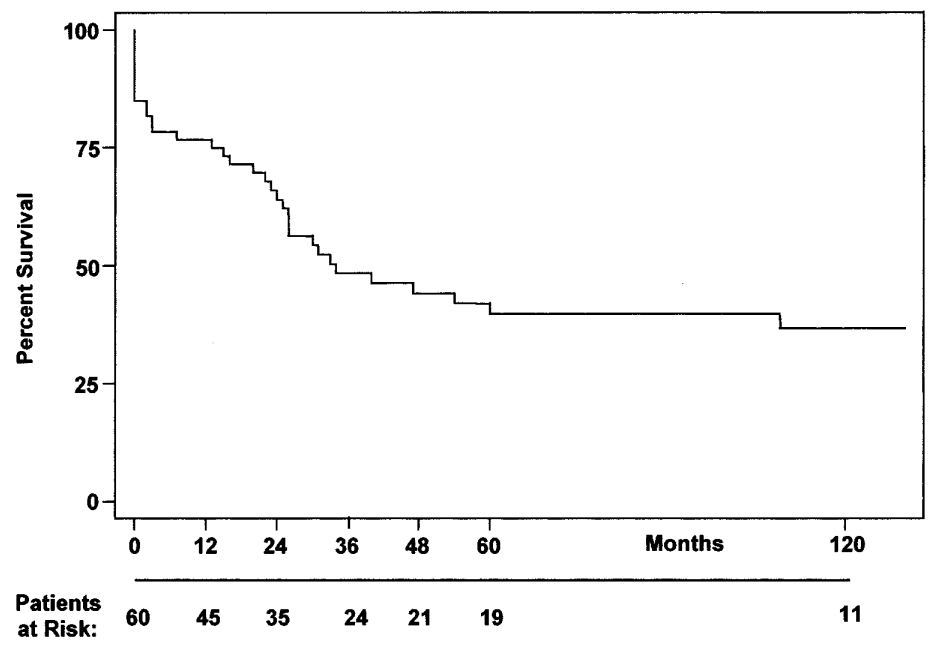

Fig 1. Overall actuarial survival after carinal resection for bronchogenic carcinoma, including operative deaths. The estimated 5-year survival was $42 \%$. There were 19 actual 5-year survivors and 11 actual 10-year survivors.

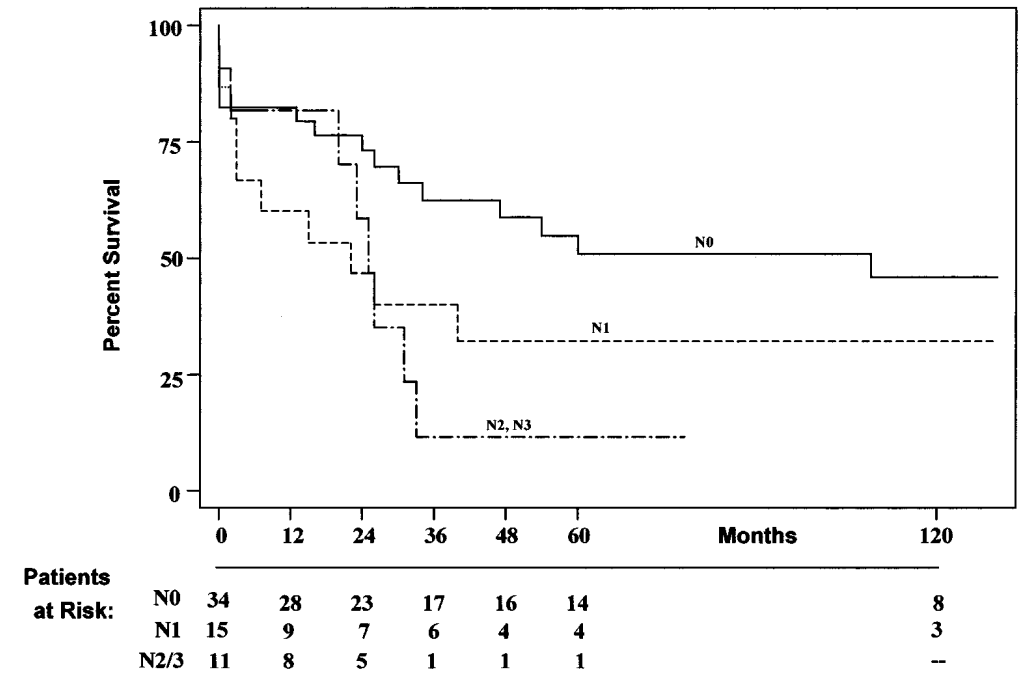

Fig 2. Actuarial survival after carinal resection for bronchogenic carcinoma, grouped by nodal status. The estimated 5-year survivals were $51 \%, 32 \%$, and $12 \%$ for N0, N1, and N2/N3, respectively.

Carinal pneumonectomy was performed in 35 patients (33 right, 2 left). Carinal resection plus removal of the right upper lobe was completed in 3 patients, and 2 additional patients had carinal and bilobar (right upper and middle lobe) resection. Two patients had excision of the carina for stump recurrence after prior pneumonectomy for carcinoma. Thirteen (22\%) patients underwent concurrent lateral resection of the superior vena cava, partial excision of the muscular wall of the esophagus, or both, because of tumor involvement.
Postoperative outcome. The overall operative mortality was $15 \%$ (9 patients) and improved from the first half of the series (20\%) to the second half (10\%). Early mortality ( $<30$ days) was noted in 5 patients, all deaths being related to the development of adult respiratory distress syndrome (ARDS). ARDS occurred exclusively after carinal pneumonectomy. Four additional operative deaths happened late ( $>30$ days), were all related to anastomotic problems, and occurred an average of 83 days after the operation. Complications were seen in 27 patients (45\%) and included atrial arrhythmias (11 
Table II. Operative procedure, detailing nodal status and outcome

\begin{tabular}{|c|c|c|c|c|c|c|c|}
\hline \multirow[b]{2}{*}{ - } & & \multicolumn{3}{|c|}{ Nodal status } & \multirow{2}{*}{$\begin{array}{l}\text { Operative } \\
\text { mortality }\end{array}$} & \multirow{2}{*}{$\begin{array}{l}\text { Operative } \\
\text { morbidity }\end{array}$} & \multirow{2}{*}{$\begin{array}{c}\text { Five-year } \\
\text { survival }\end{array}$} \\
\hline & & NO & N1 & $N 2 / 3$ & & & \\
\hline Carinal pneumonectomy, n (\%) & 35 & 15 & 13 & 7 & $7(20 \%)$ & $16(46 \%)$ & $38 \%$ \\
\hline Carinal resection and reconstruction, $\mathrm{n}(\%)$ & 18 & 13 & 1 & 4 & $2(11 \%)$ & $7(39 \%)$ & $51 \%$ \\
\hline Carinal plus lobar resection, n (\%) & 5 & 4 & 1 & 0 & 0 & $3(60 \%)$ & $40 \%$ \\
\hline Carinal resection after prior pneumonectomy, n (\%) & 2 & 2 & 0 & 0 & 0 & $1(50 \%)$ & $50 \%$ \\
\hline Totals, n (\%) & 60 & 34 & 15 & 11 & $9(15 \%)$ & $27(45 \%)$ & $42 \%$ \\
\hline
\end{tabular}

patients), anastomotic problems (10 patients), ARDS (6 patients), pneumonia (4 patients), and vocal cord paralysis ( 2 patients). Mortality and morbidity rates are further broken down by operative procedure in Table II. The median hospital stay was 10 days.

Margins and nodal status. A microscopic positive resection margin was noted in 9 patients, consisting of diffuse carcinoma-in-situ (5 patients) and invasive carcinoma (4 patients). This occurred when the maximal length of airway had been resected to permit safe (minimal anastomotic tension) reconstruction. The positive margin group had a greater mean length of airway resected $(3.3 \mathrm{~cm})$ and a somewhat higher incidence of anastomotic problems (2/9 patients, 22\%) compared with those patients with a negative margin $(2.4 \mathrm{~cm}$; $8 / 51$ patients, $16 \%$ ). The presence and extent of nodal metastases is shown in Table II.

Further therapy. Thirty-three patients underwent postoperative radiotherapy. Four patients had further procedures related to their carinal surgery, all due to anastomotic problems. These complications were treated with granulation removal $(\mathrm{n}=1)$, stenting with $\mathrm{T}$ tubes $(\mathrm{n}=1)$, or carinal re-resection $(\mathrm{n}=2)$.

Survival and long-term outcome. Complete followup was achieved in $90 \%$ of the patients, with a mean follow-up time of 59 months. The overall actuarial 5year survival, including operative deaths, was $42 \%$ (Fig 1), with 19 actual 5-year survivors and 11 actual 10year survivors. Analysis of survival with respect to nodal status is shown in Fig 2. Patients without lymph node involvement (N0) had a survival of $51 \%$, compared with $32 \%$ for patients who had involvement of N1 nodes and $12 \%$ for those with involvement of mediastinal nodes (N2/N3). Excluding operative deaths, patients with N0-1 disease had a significantly better 5year survival than patients with N2/N3 disease (48\% vs $12 \% ; P=.02)$. Survival data by operative procedure are detailed in Table II. Patients who underwent isolated carinal resection and reconstruction had the highest 5year survival of the various operative procedures at $51 \%$. The presence of microscopic positive margins
Table III. Operative mortality and 5-year survival in selected series of bronchogenic carcinoma treated with carinal resection

\begin{tabular}{|c|c|c|c|}
\hline First author $(y)$ & $n$ & $\begin{array}{c}\text { Operative } \\
\text { mortality* }(\%)\end{array}$ & $\begin{array}{c}\text { Five-year } \\
\text { survival }(\%)\end{array}$ \\
\hline Jensik $(1982)^{5}$ & 34 & 29 & 15 \\
\hline Deslauriers $(1989)^{6}$ & 38 & 30 & 13 \\
\hline Tsuchiya $(1990)^{7}$ & 20 & 40 & NR \\
\hline Vogt-Moykopf $(1991)^{8}$ & 78 & 17 & NR \\
\hline Watanabe $(1994)^{9}$ & 18 & 17 & NR \\
\hline Maeda $(1993)^{10}$ & 31 & 16 & 40 \\
\hline Roviaro $(1994)^{11}$ & 28 & 4 & $20 \dagger$ \\
\hline Dartevelle $(1996)^{12}$ & 60 & 6.6 & 43 \\
\hline Mitchell (2000) & 60 & 15 & 42 \\
\hline
\end{tabular}

$N R$, Not reported,

*Includes both early and late mortality

$\dagger$ Calculated from reported data.

(mean follow-up: 54 months) did not appear to affect survival $(P=.9)$, nor did the administration of postoperative radiotherapy $(P=.2)$. Anastomotic tumor recurrence was noted in 2 patients; both patients had negative resection margins and received adjuvant radiotherapy. Eleven additional patients had what were believed to be distant metastases from their original carcinoma, for a total recurrence rate of $22 \%$.

\section{Discussion}

Bronchogenic carcinoma approaching or involving the carina continues to be infrequently treated with surgical resection because of the perceived complexity of the procedure, the concern regarding operative morbidity and mortality, and the uncertainty over long-term survival. Table III gives operative and 5-year survival data in selected series. However, the ability to provide bronchoplastic techniques such as carinal resection and reconstruction can dramatically change the course of therapy in these patients ${ }^{13}$ and, in those with localized disease, offers the best chance of cure. In this retrospective study, we present our results in 60 patients who underwent carinal resection for bronchogenic car- 
cinoma, including long-term survival data. Although this report is one of the largest published series to date, it may be subject to criticism because of the relatively small number of patients and the long accrual period for the study (1973-1998).

The overall operative mortality in this series was $15 \%$, and it improved over the study period from the first half $(20 \%)$ to the second half $(10 \%)$. This mortality rate was higher than that of our patients undergoing carinal surgery for other airway neoplasms (8\%), likely because of increased patient age (55.6 years vs 40.2 years) and associated comorbidity. ${ }^{2}$ Combining 16 different studies for bronchogenic carcinoma involving the carina over the past 34 years, a weighted operative mortality of $16.4 \%$ can be calculated from data encompassing 396 patients. ${ }^{5-19}$ Before the past decade, several large series reported mortality figures for bronchogenic carcinoma involving the carina ranging from $29 \%$ to $40 \%,{ }^{6-8}$ prompting discussion of whether therapy should be offered to patients when the associated mortality rate exceeded the anticipated likelihood of survival. In the past several years, however, significant improvement in operative mortality has been reported by Roviaro and associates ${ }^{11}$ (4\%) and Dartevelle and colleagues $^{12}(6.6 \%)$. Our data, particularly over the last half of the series, are consistent with these later studies and support the idea that this type of operation can be safely performed with acceptable mortality rates.

Essentially all of the operative mortality in this series could be linked to the development of either ARDS (5 early deaths) or anastomotic complications (4 late deaths). The exact cause of ARDS or noncardiogenic pulmonary edema in the postoperative setting is unknown..$^{20}$ It remains a devastating problem in carinal surgery, with mortality rates as high as $90 \%,{ }^{2}$ and in the present series it was seen exclusively after carinal pneumonectomy. Our institution has reported some success in treating ARDS after pulmonary resection using inhaled nitric oxide, ${ }^{21}$ although this modality has not been used yet in patients with carinal disease. The development of anastomotic complications is likely due to technical factors at the time of airway resection and reconstruction. Significant tension on the newly constructed anastomosis, either through ineffective use of release maneuvers or through excessive airway resection, can lead to anastomotic separation, fistula, and late stenosis. Airway resection should be limited to a maximum of $4 \mathrm{~cm}$, underscoring the importance of careful preoperative assessment. Avoidance of airway devascularization, precise anastomotic suture placement, and careful handling of tissues remain key features in minimizing anastomotic problems. Finally, every effort should be made to extubate these patients at the end of the procedure, because the need for prolonged postoperative mechanical ventilation is strongly correlated with postoperative mortality. ${ }^{2}$

The overall actuarial 5-year survival in this series, including operative deaths, was $42 \%$, with 19 actual 5year survivors. Patients without nodal involvement (N0) or with limited involvement (N1) had substantially better survival than did patients who had involvement of mediastinal (N2/N3) nodes (48\% vs $12 \%$, respectively). These results are remarkably consistent with the survival data reported by Maeda and cowork$\mathrm{ers}^{10}$ and particularly Dartevelle and Macchiarini. ${ }^{12}$ In the latter series, the estimated 5-year survival was $43 \%$, with a significant survival advantage noted in patients without mediastinal nodal involvement $(P=.02)$. These statistics are considerably better than those from earlier reported series. ${ }^{5,6}$ Several reasons may account for the observed improvement in survival. Refinements in surgical and anesthetic techniques as well as advances in postoperative care have certainly contributed to the reduction in the substantial operative mortality rate. However, improved patient selection has probably had the biggest impact on patient survival. The importance of careful assessment for distant metastatic disease and detailed evaluation as to who can tolerate the physiologic impact of the operation cannot be underestimated.

In this series, 13 patients (22\%) had recurrent carcinoma, with the mode of failure primarily being distant metastases. The 2 patients who did have an anastomotic recurrence had documented negative airway margins at initial resection. The presence of a positive margin did not adversely affect survival $(P=.9)$, likely because of the predominance of carcinoma-in-situ in the positive margin group. The presence of carcinoma-in-situ at the bronchial resection margin, compared with microscopic invasive disease, has been reported to have a negligible effect on survival. ${ }^{22,23}$ Despite these findings, every attempt should be made to perform a complete resection with negative margins, documented by frozen section analysis at the time of the operation. A positive margin should be accepted only if further resection is precluded by excessive risk imposed on the planned airway reconstruction.

Further work from institutions with considerable experience in carinal resection is needed to better define the long-term outcome for patients with bronchogenic carcinoma in close proximity to or involving the carina. However, as refined surgical techniques and better patient selection have led to a considerable reduction in the operative mortality rate, this study and others suggest reasonable survival results may be expected in the absence of involved mediastinal nodes or distant metastatic disease. 
We thank Robert H. Riffenburgh, $\mathrm{PhD}$, for his assistance in the preparation of this manuscript.

Received for publication July 6, 2000; revisions requested Sept 7, 2000; revisions received Oct 12, 2000; accepted for publication Nov 6, 2000.

Address for reprints: Douglas J. Mathisen, MD, Chief, General Thoracic Surgery, Massachusetts General Hospital, Blake Bldg, 1570, Boston, MA 02114. E-mail: (mathisen.douglas@mgh.harvard.edu)

\section{REFERENCES}

1. Grillo HC. Carinal reconstruction. Ann Thorac Surg 1982;34:356-73.

2. Mitchell JD, Mathisen DJ, Wright CD, Wain JC, Donahue DM, Moncure AC, et al. Clinical experience with carinal resection. J Thorac Cardiovasc Surg 1999;117:39-53.

3. Mathisen DJ, Grillo HC. Endoscopic relief of malignant airway obstruction. Ann Thorac Surg 1989;48:469-75.

4. Riffenburgh RH. Statistics in medicine, 1st ed. San Diego: Academic Press; 1999. p. 457-65.

5. Jensik RJ, Faber LP, Kittle CF, Miley RW, Thatcher WC, El-Baz $\mathrm{N}$. Survival in patients undergoing tracheal sleeve pneumonectomy for bronchogenic carcinoma. J Thorac Cardiovasc Surg 1982;84:489-96.

6. Deslauriers J, Beaulieu M, McClish A. Tracheal sleeve pneumonectomy. In: Shields TW, editor. General thoracic surgery, 3rd ed. Philadelphia: Lea \& Febiger; 1989. p. 382-7.

7. Tsuchiya R, Goya T, Naruke T, Suemasu K. Resection of tracheal carina for lung cancer. J Thorac Cardiovasc Surg 1990;99:77987.

8. Vogt-Moykopf I, Meyer G, Naunheim K, et al. Bronchoplastic techniques for lung resection. In: Baue AE, editor. Glenn's thoracic and cardiovascular surgery, 5th ed. Norwalk: Appleton and Lange; 1991. p. 403-17.

9. Watanabe Y. Tracheal sleeve pneumonectomy. In: Shields TW, editor. General thoracic surgery, 4th ed. Baltimore: Williams and Wilkins; 1994. p. 493-501.

10. Maeda M, Nakamoto K, Tsubota N, Okada T, Katsura H. Operative approaches for left-sided carinoplasty. Ann Thorac Surg 1993;56:441-6.
11. Roviaro GC, Varoli F, Rebuffat C, Scalambra SM, Vergani C, Sibilla E, et al. Tracheal sleeve pneumonectomy for bronchogenic carcinoma. J Thorac Cardiovasc Surg 1994;107:13-8.

12. Dartevelle P, Macchiarini P. Carinal pneumonectomy for bronchogenic carcinoma. Semin Thorac Cardiovasc Surg 1996;8:41425.

13. Wood DE, Vallieres E. Tracheobronchial resection and reconstruction. Arch Surg 1997;132:850-6.

14. Mathey J, Binet JP, Galey JJ, Evrard C, Lemoine G, Denis B. Tracheal and tracheobronchial resections: technique and results in 20 cases. J Thorac Cardiovasc Surg 1966;51:1-13.

15. Ishihara T, Ikeda T, Inoue H, Fukai S. Resection of cancer of lung and carina. J Thorac Cardiovasc Surg 1977;73:936-43.

16. Fujimura S, Kondo T, Imai T, Yamauchi A, Handa M, Okabe T, et al. Prognostic evaluation of tracheobronchial reconstruction for bronchogenic carcinoma. J Thorac Cardiovasc Surg 1985;90: 161-6.

17. Muscolino G, Valente M, Ravasi G. Anterior thoracotomy for right pneumonectomy and carinal reconstruction in lung cancer. Eur J Cardiothorac Surg 1992;6:11-4.

18. Kondo T, Sagawa M, Sato M, Matumura Y, Kubo Y, Yosida H, et al. Left sleeve pneumonectomy performed through a clamshell incision with extracorporeal membrane oxygenation for bronchogenic carcinoma: report of two cases. Surg Today 1999;29: 807-10.

19. Jalal A, Jeyasingham K. Bronchoplasty for malignant and benign conditions: a retrospective study of 44 cases. Eur J Cardiothorac Surg 2000;17:370-6.

20. Kutlu CA, Williams EA, Evans TW, Pastorino U, Goldstraw P. Acute lung injury and acute respiratory distress syndrome after pulmonary resection. Ann Thorac Surg 2000;69:376-80.

21. Mathisen DJ, Kuo EY, Hahn C, Moncure AC, Wain JC, Grillo $\mathrm{HC}$, et al. Inhaled nitric oxide for adult respiratory distress syndrome after pulmonary resection. Ann Thorac Surg 1998;66: 1894-902.

22. Massard G, Doddoli C, Gasser B, Ducrocq X, Kessler R, Schumacher C, et al. Prognostic implications of a positive bronchial resection margin. Eur J Cardiothorac Surg 2000;17: $557-65$.

23. Snijder RJ, Brutel de la Riviere A, Elbers HJ, van den Bosch JM. Survival in resected stage I lung cancer with residual tumor at the bronchial resection margin. Ann Thorac Surg 1998;65:212-6.

\section{Availability of Journal back issues}

As a service to our subscribers, copies of back issues of The Journal of Thoracic and Cardiovascular Surgery for the preceding 5 years are maintained and are available for purchase from Mosby until inventory is depleted. The following quantity discounts are available: $25 \%$ off on quantities of 12 to 23 , and one third off on quantities of 24 or more. Please write to Mosby, Subscription Customer Service, 6277 Sea Harbor Dr, Orlando, FL 32877, or call 800-654-2452 or 407-345-4000 for information on availability of particular issues and prices. If unavailable from the publisher, photocopies of complete issues may be purchased from Bell \& Howell Information and Learning, 300 N Zeeb Rd, Ann Arbor, MI 48106-1346; 734-761-4700 or 800-521-0600. 